\title{
Identifikasi Penerapan Dan Pemahaman Kesehatan Dan Keselamatan Kerja Dengan Metode Hazard And Operability Study (HAZOP) Pada UMKM Eka Jaya
}

\author{
Sri Rahayuningsih ${ }^{(1)}$ \\ ${ }^{(1)}$ Program Studi Teknik Industri, Fakultas Teknik, Universitas Kadiri \\ Email : sri.nuning@gmail.com ${ }^{(1)}$
}

\begin{abstract}
Abstrak
Penelitian ini bertujuan untuk mengetahui risiko-risiko jika tidak menerapkan dan memahami tentang Keselamatan dan Kesehatan Kerja (K3) saat bekerja di area UMKM Eka Jaya yang beralamat di Jl. Moh. Hatta, RT 04, RW 03, Sembung, Tulungagung Jawa Timur. Dalam penelitian ini menggunakan metode Metode Hazard And Operability Study (HAZOP) yang bertujuan untuk mengidentifikasi risiko-risiko dalam area kerja tersebut. Dengan metode ini, didapat hasil penelitian HAZOP berupa bidang antara lain : titik kajian, parameter, kata kunci, penyebab, akibat. Selain itu, juga digunakan penilaian risiko untuk menentukan nilai likelyhood dan severity, kemudian penentuan peringkat risiko dengan tabel matriks risiko dan penilaian risiko. Setelah melihat kasus dan identifikasi masalah, objek yang di teliti yaitu: Mesin pengaduk, Bak perendaman, Suhu dalam area kerja outdoor dan indoor. Kemudian masuk ke tahap potensi bahaya, dikelompokkan menurut penilaian yang terjadi, jika risiko rendah diberi warna hijau, sesuaikan dengan tabel matriks dan nilai risiko. Setelah identifikasi permasalahan tersebut, didapat hasil bahwa risiko tidak memakai alat pelindung diri masuk kategori rendah, suhu tinggi waktu proses penggorengan masuk kategori sedang, terpeleset saat di bak perendaman, kelalaian pengoperasian mesin karena mesin tidak tertutup bagian v-belt masuk kategori tinggi, dalam hal desain adalah menyediakan ruang terbuka untuk pekerja divisi penggorengan.
\end{abstract}

Kata Kunci: HAZOP, Likelyhood, Matriks, Risiko, Severity, V-belt

\begin{abstract}
This study aims to determine the risks if you do not apply and understand about Occupational Safety and Health (K3) while working or in the Eka Jaya UMKM area located at Jl. Moh. Hatta, RT 04, RW 03, Sembung, Tulungagung- East Java. In this study using the method of the Hazard And Operability Study Method (HAZOP) which aims to identify risks in the work area. With this method, obtained HAZOP sheets in the form of fields such as: Point of study, Parameters, Keywords, Causes, Effects. In addition, risk assessment is also used to determine the value of likelyhood and severity, then determine risk ratings with risk matrix tables and risk assessments. After seeing the case and identifying the problem, the object being examined is: a stirring machine, a soaking tub, a temperature in the outdoor and indoor work area. Then enter the potential hazard stage, categorize according to the assessment that occurs, if the low risk gives a green color, adjust it to the matrix table and the riskvalue. After identifying these problems, we found that the risk of not wearing personal protective equipment was in the low category, high temperature during the medium frying process, slipping while in the immersion bath, neglecting the operation of the machine because the machine was not covered by v-belt in the high category, in terms of design is to provide open space for frying division workers.
\end{abstract}


Keyword : HAZOP, Likelyhood, Matrix, Risk, Severity, V-belt

\section{Pendahuluan}

Usaha mikro, kecil, menengah atau biasa disebut UMKM adalah suatu usaha yang berdiri dari rumah tangga yang mayoritas diproduksi sendiri dan fleksibel serta mampu menyesuaikan diri terhadap kondisi pasar yang berubah dengan cepat dibanding dengan perusahaan skala besar [1],[2],[3]. Peran UMKM dalam perekonomian memang besar, seperti UMKM EKA JAYA yang beralamat di Jl. Moh. Hatta, RT 04, RW 03, Sembung, Tulungagung yang bergerak di bidang kuliner yaitu kerupuk rambak. Usaha ini berdiri tahun 1995 didirikan oleh bapak Mudjito sampai saat ini ada 15 pekerja, jika banyak pesanan maka pemilik usaha akan mencari orang juga berjualan. Saat awal merintis usaha ini, sangat mudah karena banyak tersedianya kulit dari sapi maupun kerbau yang berasal dari hewan ternak yang beliau beli hanya kulitnya saja kemudian diolah serta dibantu oleh istrinya. Dari tahun-ketahun, permintaan kerupuk rambak meningkat [4],[5], seperti dikirim ke restoran-restoran, maupun warung pinggir jalan, tapi semakin lama teknologi berkembang, usaha mikro ini tidak dapat mengikuti arus perkembangan secara cepat. Ini yang menjadi kendala, disamping tidak begitu tahu tentang perkembangan teknologi yang pesat ini, juga terjadi kekurang-pahaman tentang keselamatan dan kesehatan kerja saat bekerja [6],[7]. Pada akhirnya, dalam hal penjualan masih terbatas di area tulungagung, tapi hebatnya usaha mikro ini sudah masuk di internet bisa diketik "Eka Jaya Kerupuk Rambak" nanti akan muncul. Dalam hal teknologi, peneliti hanya memberitahu secara singkat, karena batasan masalah peneliti adalah tentang penerapan Keselamatan Dan Kesehatan Kerja (K3) [8],[9],[10],[11].

Dalam bekerja kecelakaan atau kejadian berbahaya sekecil apapun tidak boleh diabaikan oleh pekerja, karena jika terlalu sering diabaikan akan berdampak buruk bagi pekerja dan perusahaan baik skala perusahaan kecil maupun besar [12]. Jika sesuatu hal atau kejadian yang membahayakan dalam bekerja diabaikan, maka perusahaan akan mengalami kerugian baik dari segi material bahan, waktu, kualitas serta pekerja. Dengan hal tersebut, perusahaan lambat laun akan gulung tikar. Dari kasus lapangan yang ada, penerapan kesehatan dan keselamatan kerja masih sangat minim dilakukan, baik itu perusahaan sudah tahu hal tersebut dan belum menerapkan maupun belum tahu sama sekali.

\section{Metode Penelitian}

\subsection{Model Pengukuran}

Metode untuk mengurangi risiko bahaya dalam bekerja di area pencampuran bumbu dan perendaman krecek rambak menggunakan Hazard And Operability Study (HAZOP). Berikut lembar HAZOP yang disajikan [13],[14],[15],[16]:

1. Titik kajian adalah melakukan penentuan objek yang sedang diamati.

2. Parameter adalah acuan yang digunakan untuk melakukan penelitian seperti : suhu, pencahayaan.

3. Kata kunci digunakan sebagai panduan yang membantu untuk mengidentifikasi kemungkinan terjadinya bahaya.

4. Penyebab adalah hal-hal yang mempengaruhi adanya kemungkinan potensi bahaya [17],[18]

5. Akibat adalah hal-hal yang terjadi akibat adanya suatu bahaya [19],[10],[20] 
Tabel 1 Parameter Kemungkinan Penyimpangan

\begin{tabular}{|c|c|c|}
\hline \multirow{4}{*}{ Aliran } & Tidak ada & Tidak ada aliran \\
\hline & Tinggi & $\begin{array}{c}\text { Peningkatan secara } \\
\text { kuantitatif }\end{array}$ \\
\hline & Rendah & $\begin{array}{c}\text { Penurunan secara } \\
\text { kuantitatif }\end{array}$ \\
\hline & Balik arah & Berlawanan arah \\
\hline \multirow[t]{2}{*}{ Tekanan } & Tinggi & Lebih dari normal \\
\hline & Rendah & Kurang dari normal \\
\hline \multirow[t]{2}{*}{ Temperatur } & Tinggi & Lebih dari normal \\
\hline & Rendah & Kurang dari normal \\
\hline \multirow[t]{2}{*}{ Tingkat } & Lebih & Lebih dari normal \\
\hline & Kurang & Kurang dari normal \\
\hline \multirow{4}{*}{ Komposisi } & \multirow{4}{*}{$\begin{array}{c}\text { Hampir sama, sama } \\
\text { baiknya }\end{array}$} & $\begin{array}{c}\text { Adanya padat dalam cairan } \\
\text { (jika ada) }\end{array}$ \\
\hline & & Timbul Karat \\
\hline & & Timbul Ledakan \\
\hline & & Diluar Spesifikasi \\
\hline Lainnya & $\begin{array}{l}\text { Kontaminasi, kebocoran, } \\
\text { tumpahan, pemeliharaa, } \\
\text { erosi, korosi dan racun }\end{array}$ & $\begin{array}{c}\text { Limbah yang } \\
\text { mempengaruhi lingkungan }\end{array}$ \\
\hline Mulai/ Akhir & Masalah & \\
\hline
\end{tabular}

Sumber : [21]

Tabel 2 Kata Kunci HAZOP

\begin{tabular}{|c|l|l|}
\hline Kata Kunci & $\begin{array}{c}\text { Penyimpangan yang } \\
\text { terjadi dari desain yang } \\
\text { sudah ada }\end{array}$ & \multicolumn{1}{|c|}{ Tanda-tanda } \\
\hline Tidak ada & $\begin{array}{l}\text { Tidak menghasilkan dan } \\
\text { tidak terjadi apa-apa }\end{array}$ & $\begin{array}{l}\text { Tidak ada operasi, } \\
\text { kerusakan, proses yang } \\
\text { salah dan kegagalan lainnya }\end{array}$ \\
\hline Balik arah & Operasi yang berlawanan & Arus balik \\
\hline Lebih dari & $\begin{array}{l}\text { Peningkatan secara } \\
\text { kualitatif }\end{array}$ & $\begin{array}{l}\text { Aliran, tekanan, temperatur } \\
\text { dan konsentrasi }\end{array}$ \\
\hline Kurang dari & $\begin{array}{l}\text { Penurunan secara } \\
\text { kualitatif }\end{array}$ & Dilihat kembali \\
\hline Bagian dari & $\begin{array}{l}\text { Penurunan secara } \\
\text { kualitatif }\end{array}$ & $\begin{array}{l}\text { Komponen tercampur, } \\
\text { sehingga akan mengalami } \\
\text { perubahan faa dan } \\
\text { spesifikasi }\end{array}$ \\
\hline Lebih dari & $\begin{array}{l}\text { Peningkatan komponen } \\
\text { dalam sistem }\end{array}$ & $\begin{array}{l}\text { Fasa yang kotor, udara } \\
\text { masuk }\end{array}$ \\
\hline Lainnya & Hal-hal yang akan terjadi & $\begin{array}{l}\text { Mengakhiri operasi secara } \\
\text { darurat }\end{array}$ \\
\hline
\end{tabular}

Sumber : [22] 
Setelah identifikasi potensi bahaya, dilakukan penentuan nilai risiko (menentukan nilai likelyhood dan severity) dengan tabel Risk Index [6]. Langkah-langkah sebagai berikut:

a. Menentukan tingkat kemungkinan kejadian likelyhood dengan Tabel 3.

Tabel 3 Likelyhood

\begin{tabular}{|c|l|l|}
\hline Tingkat & \multicolumn{1}{|c|}{ Uraian } & \multicolumn{1}{c|}{ Contoh Rinci } \\
\hline A & Hampir pasti terjadi & $\begin{array}{l}\text { Dapat terjadi tiap saat misalnya } \\
\text { kecelakaan lalu lintas }\end{array}$ \\
\hline B & Sering terjadi & $\begin{array}{l}\text { Terjadi beberapa kali dalam periode } \\
\text { tertentu misal kecelakaan kereta api }\end{array}$ \\
\hline C & Dapat terjadi & $\begin{array}{l}\text { Dapat terjadi tapi tidak sering misal } \\
\text { jatuh pada pengerjaan proyek }\end{array}$ \\
\hline D & Kadang-kadang & $\begin{array}{l}\text { Kadang-kadang terjadi misal } \\
\text { kebocoran instalasi nuklir }\end{array}$ \\
\hline E & Jarang sekali & $\begin{array}{l}\text { Dapat terjadi dalam keadaan tertentu } \\
\text { misal disambar petir }\end{array}$ \\
\hline
\end{tabular}

(Sumber : Olah Data)

b. Menentukan tingkat keparahan yang ditimbulkan (severity) dengan Tabel 4.

Tabel 4 Severity

\begin{tabular}{|c|l|l|}
\hline Tingkat & \multicolumn{1}{|c|}{ Uraian } & \multicolumn{1}{c|}{ Contoh Rinci } \\
\hline 1 & Tidak signifikan & $\begin{array}{l}\text { Kejadian tidak menimbulkan kerugian pada } \\
\text { manusia }\end{array}$ \\
\hline 2 & Kecil & $\begin{array}{l}\text { Menimbulkan kerugian pada manusia tapi } \\
\text { tidak berdampak serius }\end{array}$ \\
\hline 3 & Sedang & $\begin{array}{l}\text { Cedera berat dan dirawat dirumah sakit, tapi } \\
\text { tidak cacat }\end{array}$ \\
\hline 4 & Berat & Cedera parah dan cacat tetap \\
\hline 5 & Bencana & Meninggal \\
\hline
\end{tabular}

(Sumber :[15])

c. Menentukan peringkat risiko pada Tabel 5 matriks risiko dan Tabel 6 keterangan nilai risiko.

Tabel 5 Tabel Matriks Risiko

\begin{tabular}{|c|c|c|c|c|c|}
\hline \multirow{2}{*}{ Tingkat } & \multicolumn{5}{|c|}{ Konsekuensi } \\
\cline { 2 - 6 } & $\begin{array}{c}\text { Tidak } \\
\text { signifikan }\end{array}$ & Kecil & Sedang & Berat & Bencana \\
\hline A & T & T & E & E & E \\
\hline S & T & T & E & E & S \\
\hline C & R & S & T & E & E \\
\hline D & R & R & S & T & E \\
\hline E & R & R & S & T & T \\
\hline
\end{tabular}

(Sumber :[6]) 
Tabel 6 Tabel Nilai Risiko

\begin{tabular}{|l|l|}
\hline $\begin{array}{l}\text { E- Risiko } \\
\text { Ekstrim }\end{array}$ & $\begin{array}{l}\text { Kegiatan tidak boleh dilaksanakan sampai } \\
\text { risiko telah direduksi. Jika sumberdaya } \\
\text { terbatas, maka pekerjaan tidak dapat } \\
\text { dilaksanakan }\end{array}$ \\
\hline $\begin{array}{l}\text { E- Risiko } \\
\text { Tinggi }\end{array}$ & $\begin{array}{l}\text { Pertimbangan sumberdaya yang akan } \\
\text { dialokasikan untuk mereduksi risiko, } \\
\text { apabila terjadi resik saat pekerjaan } \\
\text { berlangsung, maka harus ada tindakan yang } \\
\text { dilakukan }\end{array}$ \\
\hline $\begin{array}{l}\text { E- Risiko } \\
\text { Sedang }\end{array}$ & $\begin{array}{l}\text { Perlu tindakan untuk mengurangi risiko, } \\
\text { tetapi biaya pencegahan harus } \\
\text { diperhitungkan }\end{array}$ \\
\hline $\begin{array}{l}\text { E- Risiko } \\
\text { Rendah }\end{array}$ & $\begin{array}{l}\text { Risiko dapat diterima, tidak perlu ada } \\
\text { pemantauan dan pengendalian karena sudah } \\
\text { dipastikan terpelihara }\end{array}$ \\
\hline
\end{tabular}

(Sumber :[21],[13])

\section{Hasil dan Pembahasan}

Berdasarkan instruksi kerja, pengamatan proses dan hasil wawancara ditentukan titik kajian yang dapat dilihat pada Tabel 7.

Tabel 7 Titik Kajian

\begin{tabular}{|c|c|c|}
\hline No. & Titik Kajian & Fungsi \\
\hline 1 & Mesin pengaduk & $\begin{array}{l}\text { Untuk mengaduk atau } \\
\text { mencampur krecek } \\
\text { rambak dengan bumbu } \\
\text { dapur sebelum dilakukan } \\
\text { penggorengan }\end{array}$ \\
\hline 2 & Bak perendaman & $\begin{array}{l}\text { Untuk merendam kulit } \\
\text { rambak agar lunak saat } \\
\text { diiris dan megembang } \\
\text { saat penggorengan }\end{array}$ \\
\hline 3 & $\begin{array}{l}\text { Suhu dalam area kerja } \\
\text { outdoor dan indoor }\end{array}$ & $\begin{array}{l}\text { Untuk suhu outdoor } \\
\text { adalah tergantung pada } \\
\text { sinar matahari, sedangkan } \\
\text { untuk suhu indoor } \\
\text { tergantung pada suasana } \\
\text { saat penggorengan krecek } \\
\text { rambak }\end{array}$ \\
\hline
\end{tabular}

(Sumber : Olah Data) 
Identifikasi potensi bahaya, penilaian likelyhood, penilaian severity serta nilai risiko yang diperoleh terhadap titik kajian mesin pengaduk dan bak perendaman memiliki potensi bahaya dapat dilihat pada Tabel 8 .

Tabel 8 Potensi Bahaya

\begin{tabular}{|c|c|c|}
\hline Akibat & Nilai Risiko & Potensi Bahaya \\
\hline $\begin{array}{l}\text { Tidak memakai alat } \\
\text { pelindung diri pada } \\
\text { operator mesin } \\
\text { pengaduk bumbu, } \\
\text { akan menimbulkan } \\
\text { sesak bersin-bersin } \\
\text { karena bau bumbu }\end{array}$ & $\mathrm{R}$ & $\begin{array}{c}\text { Jika tidak menggunakan } \\
\text { masker maka akan } \\
\text { terhirup bau bumbu } \\
\text { yang menimbulkan } \\
\text { bersin-bersin dan batuk }\end{array}$ \\
\hline $\begin{array}{l}\text { Perlunya penutup } \\
\text { v-belt pada mesin } \\
\text { agar lebih aman }\end{array}$ & $\mathrm{T}$ & $\begin{array}{l}\text { Jika mesin tidak ada } \\
\text { penutup v-belt akan } \\
\text { membahayakan operator } \\
\text { seperti tangan masuk ke } \\
\text { v-belt saat tidak sengaja } \\
\text { tersentuh. }\end{array}$ \\
\hline $\begin{array}{c}\text { Jika dalam bak } \\
\text { perendaman krecek } \\
\text { ada tumpahan air } \\
\text { sebaiknya segera } \\
\text { dibersihkan karena } \\
\text { dapatmencelakakan } \\
\text { pekerja } \\
\end{array}$ & $\mathrm{T}$ & $\begin{array}{c}\text { Terpeleset dan terbentuk } \\
\text { kepalanya, serta luka- } \\
\text { luka ringan pada siku } \\
\text { dan lutut. }\end{array}$ \\
\hline $\begin{array}{c}\text { Jika suhu dalam } \\
\text { indoor saat } \\
\text { menggoreng terlalu } \\
\text { panas, maka } \\
\text { pekerja akan cepat } \\
\text { lelah }\end{array}$ & E & $\begin{array}{c}\text { Ketika keadaan cepat } \\
\text { lelah akan menimbulkan } \\
\text { keringat dingin, kepala } \\
\text { pusing }\end{array}$ \\
\hline
\end{tabular}

Pada identifikasi potensi bahaya menggunakan Hazard And Operability Study (HAZOP) maka penerapan dan pemahaman Keselamatan dan Kesehatan Kerja (K3) di UMKM Eka Jaya perlu dilakukan agar lebih aman dan tidak terjadi kerugian material maupun pekerja. 


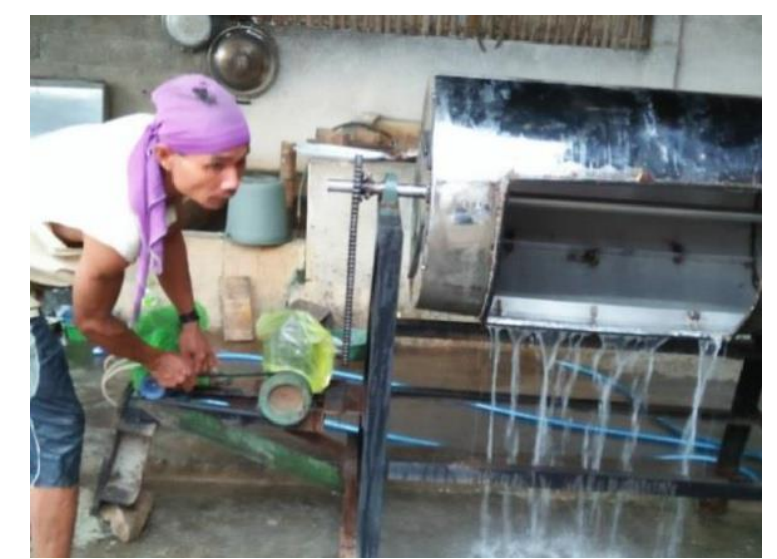

Gambar 1 Display Pengaduk Bumbu Krecek Rambak

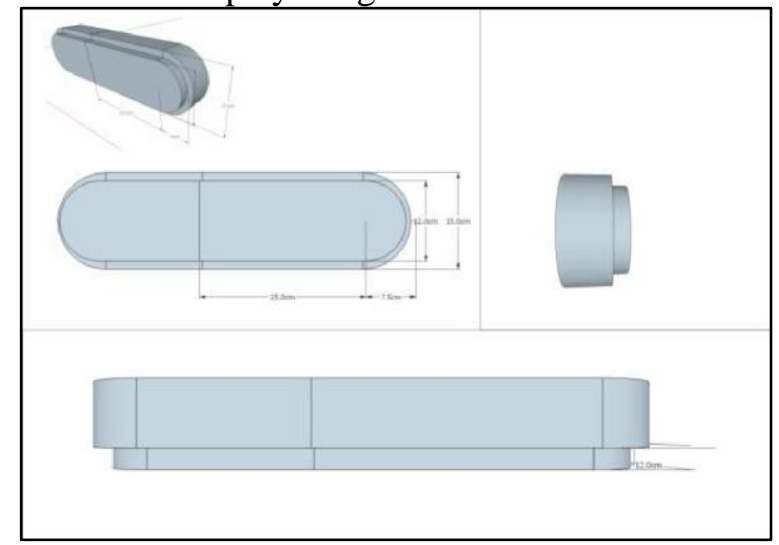

Gambar 2 Desain Rekomendasi Tutup $V$ - belt

Rekomendasi terhadap Desain adalah sebagai berikut:

a. Memasang penutup v-belt pada mesin pengaduk demi menghindari terjadinya kecelakaan kerja yang berpotensi terkena adalah tangan dan kaki [23], .

b. Menggunakan alat pelindung diri bagi operator mesin pengaduk [24],[25],[26].

c. Sering-sering mengecek lantai tempat bak perendaman krecek, karena pasti akan ada tumpahan air kapur dan jika terkena air kapur maka pekerja ketika memasukkan krecek untuk proses pengapuran akan terpeleset dan berpotensi terkana bahaya pada lutut, siku bahkan kepala.

d. Menyediakan ruang terbuka untuk pekerja bagian penggorengan agar tidak terjadi kepanasan saat menggoreng, jika terjadi kepanasan maka pekerja akan cepat lelah dan pusing.

\section{Kesimpulan}

Berdasarkan hasil identifikasi bahaya dan penilaian risiko, diperoleh potensi bahaya berdasarkan risk indeks sebagai berikut:

a. Risiko yang masuk kategori rendah meliputi : tidak memakai alat pelindung diri saat pengadukan bumbu dengan krecek.

b. Risiko yang masuk kategori sedang meliputi : jika suhu proses penggorengan tinggi maka pekerja cepat merasa lelah.

c. Risiko yang masuk kategori tinggi meliputi : terpeleset saat di bak perendaman, kelalaian saat pengoperasian mesin pengaduk karena v-belt tanpa tutup.

d. Rekomendasi terhadap desain adalah menyediakan ruang terbuka untuk pekerja bagian penggorengan 


\section{Daftar Pustaka}

[1] Y. Chrismardani, "Komunikasi Pemasaran Terpadu : Implementasi Untuk Umkm," Neo-Bis - J. Neraca, Ekon. dan Bisnis, 2014.

[2] R. Purwaningsih and P. Kusuma Damar, "Analisis Faktor-faktor yang mempengaruhi Kinerja Usaha Kecil dan Menengah (UKM) dengan Metode Structural Equation Modeling (Studi kasus UKM berbasis Industri Kreatif Kota Semarang)," E-Journal Undip, 2015.

[3] D. H. Wibowo, Z. Arifin, and . Sunarti, "Analisis Strategi Pemasaran Untuk Meningkatkan Daya Saing UMKM (Studi pada Batik Diajeng Solo),” J. Adm. Bisnis, vol. 29, no. 1, pp. 59-66, 2015.

[4] T. Siregar, Ameilia Zuliyanti, "Aneka keripik tempe bergizi dan tepat guna mendukung kedaulatan pangan," Abdimas Talent., 2018.

[5] T. Kristanto, E. C. Muliawati, R. Arief, and S. Hidayat, "Peningkatan Kualitas Produksi UKM Percetakan di Karangpilang Surabaya dan Krian Sidoarjo," AKSIOLOGIYA J. Pengabdi. Kpd. Masy., vol. 2, no. 1, pp. 33-38, 2018.

[6] D. Retnowati, "Analisa Risiko K3 Dengan Pendekatan Hazard and Operability Study (Hazop)," Tek. Eng. Sains J., vol. 1, no. 1, pp. 41-46, 2017.

[7] International Labor Organization, Meningkatkan Keselamatan dan Kesehatan Pekerja Muda. Jakarta: ILO, 2018.

[8] N. Fridayanti and R. Kusumasmoro, "Penerapan Keselamatan Dan Kesehatan Kerja Di PT Ferron Par Pharmaceuticals Bekasi," J. Adm. KANTOR, Vol. 4, No.1, Juni 2016, 211-234 PISSN 2337-6694 E-ISSN 2527-9769, vol. 4, no. 1, pp. 211-234, 2016.

[9] D. Arena, F. Criscione, and N. Trapani, "Risk assessment in a chemical plant with a CPNHAZOP Tool," IFAC-PapersOnLine, vol. 51, no. 11, pp. 939-944, 2018.

[10] F. Crawley and B. Tyler, "Chapter 2 - Process Hazard Studies," in HAZOP: Guide to Best Practice (Third Edition), Third Edition., F. Crawley and B. Tyler, Eds. Elsevier, 2015, pp. 4-9.

[11] M. [Angel de la O Herrera], A. S. Luna, A. C. A. [da Costa], and E. M. [Blanco Lemes], “A structural approach to the HAZOP - Hazard and operability technique in the biopharmaceutical industry," J. Loss Prev. Process Ind., vol. 35, pp. 1-11, 2015.

[12] D. P. Restuputri and R. P. D. Sari, "Analisis Kecelakaan Kerja Dengan Menggunakan Metode Hazard and Operability Study ( Hazop )," J. Ilm. Tek. Ind., vol. 14, no. 1, pp. 24-35, 2015.

[13] V. [Casson Moreno] and V. Cozzani, "Integrated hazard identification within the risk management of industrial biological processes," Saf. Sci., vol. 103, pp. 340-351, 2018.

[14] L. Allford and R. Gowland, "Foreword," HAZOP Guid. to Best Pract., pp. ix-xi, 2015.

[15] P. K. Marhavilas, M. Filippidis, G. K. Koulinas, and D. E. Koulouriotis, "A HAZOP with MCDM based risk-assessment approach: Focusing on the deviations with economic/health/environmental impacts in a process industry," Sustain., vol. 12, no. 3, 2020.

[16] F. Crawley and B. Tyler, "Chapter 5 - Organizing a HAZOP Study," in HAZOP: Guide to Best Practice (Third Edition), Third Edition., F. Crawley and B. Tyler, Eds. Elsevier, 2015, pp. 2942.

[17] H. P. Bloch, "Root Cause Failure Analysis," in Petrochemical Machinery Insights, 2017.

[18] L. T. Dewi, “Analisis Tingkat Resiko Bahaya Muskuloskeletal Aktivitas Industri Kecil Makanan di Yogyakarta,” J. Metris, vol. 17, pp. 107-112, 2016. 
[19] B. Yanar, M. Lay, and P. M. Smith, "The Interplay Between Supervisor Safety Support and Occupational Health and Safety Vulnerability on Work Injury," Saf. Health Work, vol. 10, no. 2, pp. 172-179, 2019.

[20] F. Crawley and B. Tyler, "Chapter 4 - The Detailed HAZOP Study Procedure," in HAZOP: Guide to Best Practice (Third Edition), Third Edition., F. Crawley and B. Tyler, Eds. Elsevier, 2015, pp. 13-28.

[21] N. Boonthum, U. Mulalee, and T. Srinophakun, "A systematic formulation for HAZOP analysis based on structural model," Reliab. Eng. Syst. Saf., vol. 121, pp. 152-163, 2014.

[22] F. Crawley and B. Tyler, Eds., "Appendix 3 - An Illustration of HAZOP Study for a Continuous Operation," in HAZOP: Guide to Best Practice (Third Edition), Third Edition., Elsevier, 2015, pp. 101-121.

[23] G. E. M. Soputan, B. F. Sompie, R. J. M. Mandagi, D. Pascasarjana, T. Sipil, and U. Sam, "MANAJEMEN RISIKO KESEHATAN DAN KESELAMATAN KERJA ( K3 ) ( Study Kasus Pada Pembangunan Gedung SMA Eben Haezar )," vol. 4, no. 4, pp. 229-238, 2014.

[24] Dickson, "Pengertian Alat Pelindung Diri dan Jenis - Jenis APD," www.produksielektronik.com, 2015. [Online]. Available: https://www.produksielektronik.com/pengertian-alat-pelindung-diriapd-k3-jenis-apd/. [Accessed: 28-Nov-2019].

[25] F. S. Lagata, "GAMBARAN PERILAKU PENGGUNAAN ALAT PELINDUNG DIRI (APD) PADA PEKERJA DI DEPERTEMEN PRODUKSI PT. MARUKI INTERNASIONAL INDONESIA MAKASSAR TAHUN 2015," UNIVERSITAS ISLAM NEGERI ALAUDDIN MAKASSAR, 2015.

[26] M. A. Bora, D. B. Tarigan, and Larisang, "Perancangan Alat Pelindung Diri ( APD ) Penutup Bahu dan Lengan yang Ergonomis pada Proses Pengelasan di PT . McDermott," vol. 2017, no. 1, pp. 4-6, 2017. 